5. González D, van der Burg M, García-Sanz $R$, et al. Immunoglobulin gene rearrangements and the pathogenesis of multiple myeloma. Blood. 2007;110(9):3112-21.

6. Martinez-Lopez J, Lahuerta JJ, Pepin F, et al. Prognostic value of deep sequencing method for minimal residual disease detection in multiple myeloma. Blood. 2014;123(20):3073-9.

7. Medina A, Jiménez $C_{\text {, }}$ Sarasquete $M E$, et al. Molecular profiling of immunoglobulin heavy-chain gene rearrangements unveils new potential prognostic markers for multiple myeloma patients. Blood Cancer J. 2020;10(2):14.

8. Paiva B, van Dongen Jj, Orfao A. New criteria for response assessment: role of minimal residual disease in multiple myeloma. Blood. 2015;125(20):3059-68.

9. Puig N, Sarasquete ME, Balanzategui A, et al. Critical evaluation of ASO RQ-PCR for minimal residual disease evaluation in multiple myeloma. $A$ comparative analysis with flow cytometry. Leukemia. 2014;28(2):391-7.

\title{
ĐÁNH GIÁ CHẤT LƯỢNG SỐNG CỦA NGƯỜI BỆNH UNG THƯ VÚ HER2-DƯO'NG TÍNH TẠI VIỆT NAM THEO THANG ĐO QLQ-C30
}

\author{
Tô Huệ Nghi*, Trần Thị Yến Nhi*, \\ Nguyễn Cao Đức Huy*, Nguyễn Thị Thu Thuỷ* \\ người bệnh.
}

\section{TÓM TẮT}

Đặt vấn đề: Ung thư vú (UTV) đã và đang trở thành mối quan tâm hàng đầu của y tế thế giới, đây là loại ung thư phổ biến nhất trên phư nữ. Việc đánh giá chất lương sống (CLS) của người bệnh UTV giúp bác sĩ cân nhắc hướng điêu trị, so sánh các phương pháp điêu trị hiên hành và đánh giá các phương pháp điều trị mới. Đề tài này nhẳm đánh giá chất lượng sống của bềnh nhân ung thư vú bằng bô câu hỏi chuyên biêt dành cho người bệnh UTV EORTC QLQ-C30. Đốî tượng và phương pháp: Nghiên cứu mô tả cắt ngang dựa trên dữ liệu thu thâp từ phiếu khảo sát và hố sơ bệnh án của người bênh UTV HER2 dương tính điều trị tại 6 bệnh viện (BV) bao gồm BV Bạch Mai, BV Ung Bướu Hà Nội, BV K Trung Ương, BV Ung Bướu Đà Nẵng, BV Ung Bướu Thành phố Hồ Chí Minh và BV Chơ Rẫy. Nghiên cứu đánh giá CLS bằng thang đo QLQ-C30 và sử dụng phép kiếm thống kê phù hợp với độ tin cậy $95 \%$. Kểt quả: Mấu nghiên cứu bao gồm 338 người bênh nữ với độ tuổi trung bình $53,87 \pm$ 9,97 tuổi, phẩn lớn mẫu thuộc giai đoạn sớm $(55,7 \%)$ và chưa di căn $(76,6 \%)$. Dựa trên thang đo QLQ-C30 nghiên cứu ghi nhận điểm CLS tổng quát có giá trị trung bình $60,11 \pm 15,80$. Ơ thang điêm chức năng, cảm xúc, thể chất và nhận thức là 3 phương diện có số điểm cao nhất với giá trị lần lướt $77,79 \pm 21,54$; $75,35 \pm 17,75$ và $74,11 \pm 22,92$. ̛̛̉ thang điểm triệu chứng, khó khăn tài chính và mất ngủ là vấn đề phổ biến và nghiêm trọng với số điểm khá cao $(55,82 \pm$ 32,69 và $37,77 \pm 30,11$; tương ứng). Kết luận: Người bệnh ung thư vú HER2-dương tính có chất lượng sống ở mức khá với điểm chất lượng sống tổng quát $60,11 \pm 15,80$ điểm. Chức năng thể chất, cảm xúc và nhận thức có điểm số tương đối tốt, tuy nhiên quá trình điều trị mang lại khó khăn tài chính cho

*Đại hoc Y Dược Thành phố Hồ Chí Minh Chịu trách nhiệm chính: Nguyễn Thị Thu Thuỷ Email: nguyenthuthuy@ump.edu.vn Ngày nhận bài: 4.6.2021

Ngày phản biện khoa học: 3.8.2021

Ngày duyệt bài: 12.8 .2021
Tư khóa: chất lượng sống, ung thư vú HER2 dương tính, QLQ-C30.

\section{SUMMARY}

EVALUATING THE QUALITY OF LIFE OF PATIENTS DIAGNOSED WITH HER2POSITIVE BREAST CANCER IN VIETNAM

\section{BASED ON THE EORTC QLQ-C30 SCALE}

Background: Breast cancer has become a leading health concern worldwide, especially in women. Evaluating the health-related quality of life (HR-QoL) on patients helps clinicians to consider the optimum treatment, compare the current with the novel therapy. This study aimed to assess the HR-QoL of breast cancer patients by using a specialized questionnaire for cancer patients (EORTC QLQ-C30). Materials and methods: $A$ cross-sectional descriptive study based on data collected from questionnaires and medical records of HER2-positive cancer patients treated at 6 hospitals including Bach Mai hospital, Cho Ray Hospital, Ho Chi Minh City Oncology Hospital, Da Nang Oncology Hospital, K Hospital, Ha Noi Oncology Hospital. Results: The survey sample included 338 patients with an average age of $53.87 \pm 9.97$ years old, most of which were in early stage $(55.7 \%)$ and had not yet metastasized (76.6\%). Based on the QLQ-C30 scale, the study recorded an overall QoL score of $60.11 \pm 15.80$. Among the functional scale, emotional, physical, and cognitive aspects had the highest score (77.79 \pm $21.54,75.35 \pm 17.75$ and $74.11 \pm 22.92$ respectively). In the symptom scale, insomnia and financial struggle were reported to be the most common and severe issues encountered during the treatment with the score of $55.82 \pm 32.69$ and 37.77 \pm 30.11 , respectively. Conclusion: HER2- positive breast cancer has moderate level of health-related quality of life. Physical, emotional, and cognitive functions had relatively good scores, however cancer treatment caused financial difficulties for patients

Keywords; quality of life, HER2-positive breast cancer, QLQ-C30. 


\section{I. ĐẶT VẤN ĐỀ}

Bệnh ung thư vú (UTV) đã và đang trở thành mối quan tâm hàng đầu của y tế thế giới, vì đây là loại ung thư phổ biến nhất trên phụ nữ với 2.261 .419 ca mới mắc năm 2020 và gây ra khoảng 685.000 cái chết mỗi năm [8]. Tại Việt Nam, có khoảng 15.000 ca mới mắc UTV trong năm 2018, đây là một con số rất đáng báo động [6]. Việc đánh giá chất lượng sống (CLS) của người bệnh (NB) UTV đóng vai trò quan trọng góp phần giúp bác sĩ cân nhắc hướng điều trị thích hợp. Bộ câu hỏi QLQ-C30 là một trong những bộ câu hỏi đặc trưng cho NB ung thư và được sử dụng phổ biến trong nhiều nghiên cứu [7]. Bộ công cụ EORTC QLQ-C30 với 30 câu hỏi ở 3 thang điểm bao gồm chức năng, triệu chứng và $C L S$ tổng quát. Mặc dù nghiên cứu CLS của NB UTV đã được thực hiện khá nhiều nhưng mang tính khu trú tại một hoặc hai bệnh viện. Vì thế, đề tài tiến hành khảo sát CLS của NB UTV sử dụng bộ câu hỏi QLQ-C30 trên cõ̃ mẫu đại diện hơn cho quần thể Việt Nam.

\section{II. ĐỐI TƯỢNG VÀ PHƯƠNG PHÁP NGHIÊN CỨU}

Đối tượng. Người bệnh UTV HER2 dương tính (HER2+) điều trị tại 6 BV bao gồm BV Bạch Mai, BV Ung Bướu Hà Nội, BV K Trung Ương, BV Ung Bướu Đà Nẵng, BV Ung Bướu Thành phố Hồ Chí Minh và BV Chợ Rẫy.

Phương pháp nghiên cứu. Nghiên cứu mô tả cắt ngang dựa trên phiếu khảo sát CLS NB UTV HER2+.

Mẫu nghiên cứu. Nghiên cứu thực hiện lấy mẫu toàn bộ trong thời gian nghiên cứu từ tháng 7 đến tháng 12/2019 thoả tiêu chí lựa chọn, loại trừ?.

Tiêu chí lựa chọn: - Được chẩn đoán UTV HER2+ theo mã ICD C50

- Có khả năng trả lời các câu hỏi trong phiếu khảo sát.

- Đồng ý tham gia nghiên cứu

\section{Tiêu chí loại trừ}

- Không hoàn thành phiếu

- Không hoàn thành điều trị do chuyển viện, tử vong hoặc tự ý xuất viện.

Biến số nghiên cứu. CLS của NB mắc UTV HER2+ được đánh giá theo thang đo EORTC QLQ-C30 gồm 30 câu hỏi chia thành 3 khía cạnh (chức năng, triệu chứng và CLS tổng quát). Mỗi câu trả lời được đánh giá theo 4 mức độ từ 1 tới 4, riêng câu hỏi về $C L S$ tổng quát sẽ được đánh giá trên thang điểm 7. Điểm các câu trả lời được quy đổi tuyến tính sang thang điểm 100 theo hướng dẫn của EORTC [10]. Theo đó, điểm thô (Raw Score) (RS) là trung bình điểm các câu hỏi cùng một vấn đề, được tính theo công thức:

$$
\text { Điểm thô }(\mathrm{RS})=\frac{\mathrm{Q}_{1}+\mathrm{Q}_{\mathrm{g}}+\cdots+\mathrm{Q}_{\mathrm{g}}}{\mathrm{n}}
$$

Điểm chức năng được tính theo công thức:

$$
\text { Điểm chức năng }=1-\frac{\mathrm{RS}-1}{3} \times 100
$$

Điểm triệu chứng được tính theo công thức:

$$
\text { Điểm triệu chứng }=\frac{\mathrm{RS}-1}{3} \times 100
$$

Điểm tổng quát được tính theo công thức:

$$
\text { Điểm CLS tổng quát }=\frac{\text { RS-1 }}{6} \times 100
$$

Xử lý và phân tích số liệu. Số liệu đề tài được xử lý và thống kê với độ tin cậy $95 \%$ bằng phần mềm thống kê SPSS 26.0 và Microsoft Excel 2019 với các phương pháp thống kê phù hợp.

\section{KẾT QUẢ NGHIÊN CỨU}

Đặc điểm mẫu nghiên cứu. Khảo sát trên 338 NB UTV HER2+ tại 6 BV nghiên cứu, đề tài

\begin{tabular}{|c|c|c|c|c|c|}
\hline \multicolumn{2}{|c|}{ Đặc điểm } & $\begin{array}{c}\text { Tần số } \\
\text { (tỉ lê \% }\end{array}$ & \multicolumn{2}{|c|}{ Đặc điểm } & $\begin{array}{c}\text { Tân số } \\
\text { (tỉ lê \% \%) }\end{array}$ \\
\hline \multirow{3}{*}{ Nơi sống } & Thành thị & $242(71,6)$ & \multirow{3}{*}{$\begin{array}{l}\text { Mức độ di } \\
\text { căn }\end{array}$} & Chưa di căn & $259(76,6)$ \\
\hline & Nông thôn & $88(26,0)$ & & Đã di căn & $24(7,1)$ \\
\hline & Miền núi, hải đảo & $8(2,4)$ & & Chưa xác định & $29(16,3)$ \\
\hline \multirow{6}{*}{$\begin{array}{l}\text { Nghề } \\
\text { nghiệp }\end{array}$} & Lao động trí óc & $71(21,0)$ & \multirow{5}{*}{$\begin{array}{l}\text { Giai đoạn } \\
\text { bệnh }\end{array}$} & Giai đoạn I & $36(10,7)$ \\
\hline & Tự kinh doanh & $44(13,0)$ & & Giai đoạn II & $152(45,0)$ \\
\hline & Lao động chân tay & $57(16,9)$ & & Giai đoạn III & $83(24,6)$ \\
\hline & Đã nghỉ hưu & $76(22,5)$ & & Giai đoạn IV & $26(7,7)$ \\
\hline & Thất nghiệp & $85(25,1)$ & & Chưa xác định & $41(12,1)$ \\
\hline & Khác** & $5(1,5)$ & \multirow{2}{*}{ Phẫu thuật } & Chưa PT & $44(13,0)$ \\
\hline \multirow{3}{*}{$\begin{array}{l}\text { Trình độ } \\
\text { học vấn }\end{array}$} & Chưa tốt nghiệp & $128(379)$ & & Đã PT & $294(87,0)$ \\
\hline & THPT & $1 \angle 0(3,9)$ & \multirow{2}{*}{ Xạ trị } & Chưa XT & $219(64,8)$ \\
\hline & Tốt nghiệp THPT & $76(22,5)$ & & Đã XT & $119(35,2)$ \\
\hline
\end{tabular}
ghi nhận đặc điểm nhân khẩu và bệnh lý trình bày trong bảng 1 .

Bảng 1. Đặc điểm nhân khẩu và bệnh lý người bệnh ung thư HER2 dương tính 


\begin{tabular}{|c|c|c|c|c|c|}
\hline & Cao đăng & $30(8,9)$ & \multirow{3}{*}{ Phác đồ } & TLĐ $\pm N T$ & $85(25,1)$ \\
\hline & Đại học & $94(27,8)$ & & $\mathrm{HT}+\mathrm{TL} \pm \mathrm{NT}$ & $240(71,0)$ \\
\hline & Sau đại học & $10(3,0)$ & & HT & $13(3,8)$ \\
\hline \multirow{6}{*}{$\begin{array}{l}\text { BV đang } \\
\text { điêu trị }\end{array}$} & Bạch Mai & $12(3,6)$ & \multirow{4}{*}{$\begin{array}{l}\text { Số bềnh } \\
\text { kèm }\end{array}$} & Không & $157(46,4)$ \\
\hline & Ung bướu Hà Nội & $18(5,3)$ & & \multirow{2}{*}{$\begin{array}{l}1 \\
2\end{array}$} & $134(39,6)$ \\
\hline & Ung bướu Đà Năng & $13(3,8)$ & & & $35(10,4)$ \\
\hline & Ung bướu TP HCM & $143(42,3)$ & & Trên 3 & \begin{tabular}{l|l} 
& $12(3,6)$ \\
\end{tabular} \\
\hline & Chợ Rây & $30(8,9)$ & Đặc điếm & GTTB \pm ĐLC & GTNN - GTLN \\
\hline & K Trung Ưong & $122(36,1)$ & Tuối & $53,87 \pm 9,97$ & $28-84$ \\
\hline
\end{tabular}

Ghi chú: *- hoạt động từ thiện, hoạt động tôn giáo; THPT - trung học phổ thông; BHYT bảo hiểm y tế; PT - phấu thuật; XT - xạ trị; HT hoá trị; TLĐ - trị liệu đích; NT - nội tiết; GTTB Giá trị trung bình; ĐLC - Độ lệch chuẩn; GTNN Giá trị nhỏ nhất; GTLN - Giá trị lớn nhất.

Theo bảng 2, toàn bộ mẫu nghiên cứu là nữ với độ tuổi trung bình $53,87 \pm 9,97 ; 71,6 \% \mathrm{NB}$ sống ở thành thị; nhóm không có việc làm chiếm tỷ lệ cao nhất $(25,1 \%)$. Đa số người bệnh chưa tốt nghiệp THPT (37,9\%), tiếp theo là tốt nghiệp Đại học trở lên $(30,8 \%)$. Phần lớn mẫu nghiển cứu tập trung tại 2 BV là BV $\mathrm{K}$ Trung Ương $(36,1 \%)$ và BV Ung Bướu TP.HCM (42,3\%).

$55,7 \%$ NB ở giai đoạn sớm (giai đoạn I, II) và $76,6 \%$ chưa di căn. Có $87,0 \%$ NB được chỉ định phẫu thuật và $71,0 \%$ sử dụng phác đồ phối hợp hoá trị và trị liệu đích. NB thuộc mẫu nghiên cứu đa phần không có bệnh kèm theo $(46,4 \%)$ hoặc chỉ có 1 bệnh (39,6\%).

Chất lượng sống theo thang đo EORTC QLQ-C30. CLS của mẫu nghiên cứu được đánh giá dựa trên thang đo QLQ-C30 với 3 khía cạnh chức năng, triệu chứng và CLS tổng quát.

Khía canh chức năng. Khía canh chức năng bao gổm 5 phương diện: thể chất, vai trò, cảm xúc, nhận thức và xã hội. Kết quả khảo sát khía cạnh chức năng được trình bày trong Hình 1.

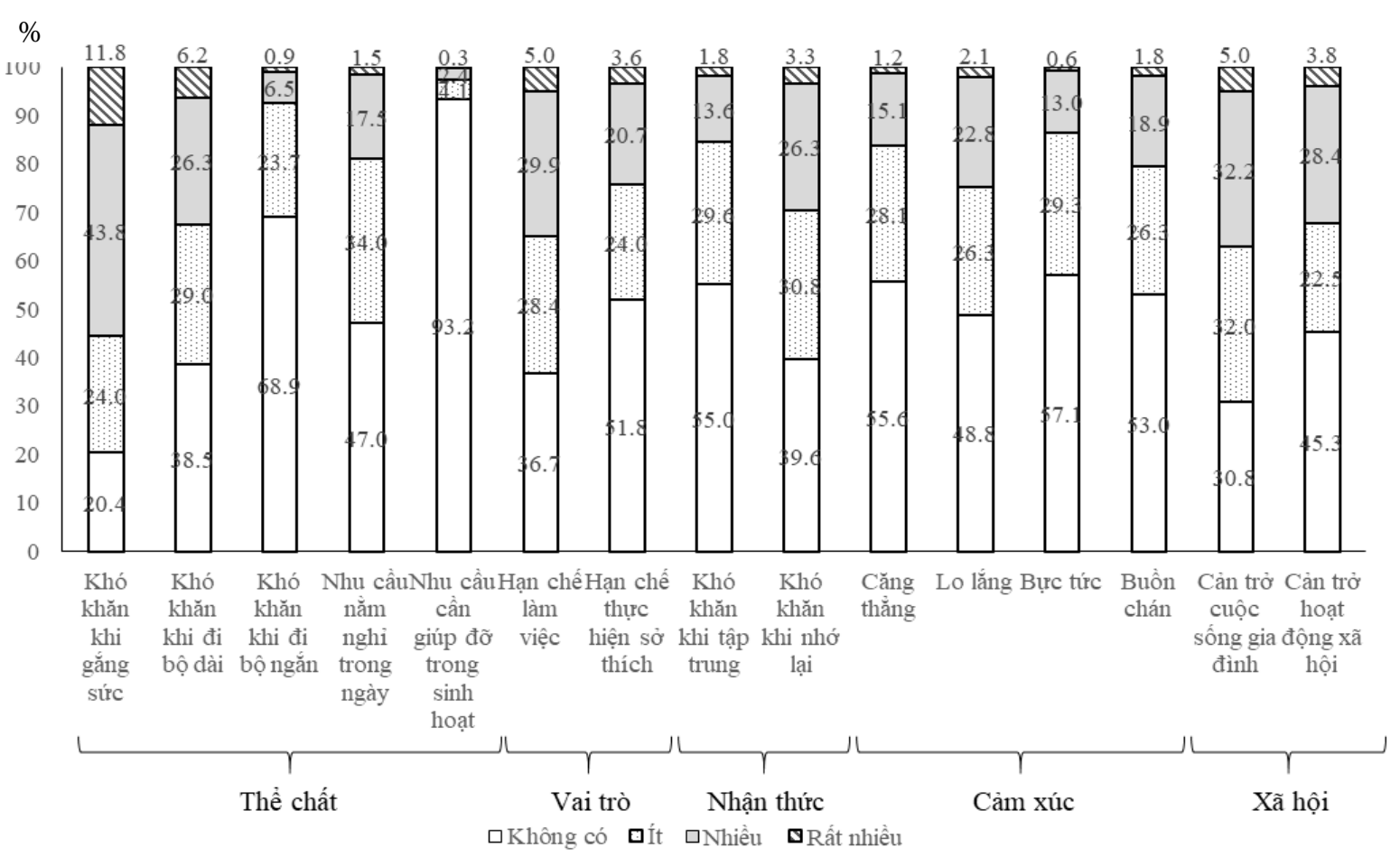

Hình 1. Đánh giá các khía cạnh trong thang điểm chức năng

Theo hình 1 , đề tài ghi nhận những kết quả sau đây:

- Xét phương diện thể chất, gần $80 \%$ NB gặp khó khăn khi gắng sức ở các mức độ từ nhẹ đển rất nặng. Trong hoạt động đi lại, đa số NB không gặp trở ngại khi đi bộ quãng đường ngắn $(68,9 \%)$. Nhưng đối với quãng đường dài, chỉ có khoảng 1/3 mẫu ñ̃ghiên cứu không gặp khó khăn. Gần một nửa mẫu nghiên cứu không cần nghỉ ngơi (chiếm 47,0\%). Phần lớn NB không cần sự 
giúp đỡ khi thực hiện các công việc cơ bản như ăn mặc, tắm rửa, đi vệ sinh (chiếm 93,2\%).

- Xét phương diên vai trò, hơn 1/3 NB không bị hạn chế trong cổng việc $(36,7 \%)$ và hơn một nửa NB không gặp hạn chế khi thực hiện sở thích cá nhân (51,8\%). Nhóm người bị hạn chế ít có tỉ lệ xấp xỉ nhau ở cả hai câu hỏi, với $28,4 \%$ hạn chế trong công việc và $24,0 \%$ hạn chế thực hiện sở thích. Tỉ lệ này giảm dần khi mức độ hạn chế tăng dần trong công việc hằng ngày và trong thực hiện sở thích cá nhân, cụ thể là $29,9 \%$ và $20,7 \%$ ở mức độ nhiều; và $5,0 \%$ và $3,6 \%$ tương ứng ở mức độ rất nhiều.

- Xét phương diện nhận thức, hơn 1/3 NB không gặp khó khăn khi nhớ lại $(39,6 \%)$ và hơn một nửa NB không bị mất tập trung $(55,0 \%)$. Nghiên cứu còn ghi nhận tỉ lệ xấp xỉ ở nhóm khó tập trung và khó nhớ lại ở mức độ nhẹ (29,6\% và $30,8 \%$ tương ứng). Tuy nhiên, tỉ lệ người hay quên mức độ nghiêm trọng đến rất nghiêm trọng (lân lượt $26,3 \%$ và $3,3 \%$ ) tăng cao gấp đôi so với nhóm khó tập trung (lần lượt 13,6\% và 1,8\%).

- Xét phương diện cảm xúc, nhóm NB không có vấn đề về tâm lý chiếm $50 \%$ mẫu nghiên cứu, cụ thể $55,6 \%$ cảm thấy không căng thẳng; $48,8 \%$ không lo lắng; $57,1 \%$ không cáu gắt và $53,0 \%$ không buồn chán. Những NB còn lại gặp các thay đổi về cảm xúc với đa số ở mức độ ít với tỉ lệ dao động từ 26,3\% đến $29,3 \%$ tùy trạng thái, mức độ nhiêu chỉ gặp ở $13,0-22,6 \%$ và các thay đổi ở mức độ rất nhiều không đáng kể (dưới 2,2\%).

- Xét phương diện xã hội, cản trở cuộc sống gia đình ở các mức độ từ không có đến nặng khá đồng đều tương ứng với các tî lệ 30,8\%; 32,0\% và $32,2 \%$; chỉ một phần nhỏ (khoảng $5,0 \%$ ) ở mức độ nghiêm trọng. Xét khía cạnh hoạt động xã hội, 45,3\% NB không bị bệnh làm hạn chế các hoạt động bên ngoài, gấp đôi so với nhóm ít hạn chế $(22,5 \%)$ và nhóm nhiều hạn chế $(28,4 \%)$.

Điểm chức năng của mẫu nghiên cứu được thể hiện tại Hình 1. Theo đó, đề tài ghi nhận hầu hết các chức năng đều trên 70 điểm, trong đó cảm xúc có điểm CLS cao nhất $(77,79 \pm 21,54)$. Các khía cạnh khác có giá trị giảm dần bao gồm thể chất $(75,35 \pm 17,75)$; nhận thức $(74,11 \pm$ $22,92)$; vai trò $(70,12 \pm 27,20)$; và thấp nhất là phương điện xã hội $(66,27 \pm 27,44)$.

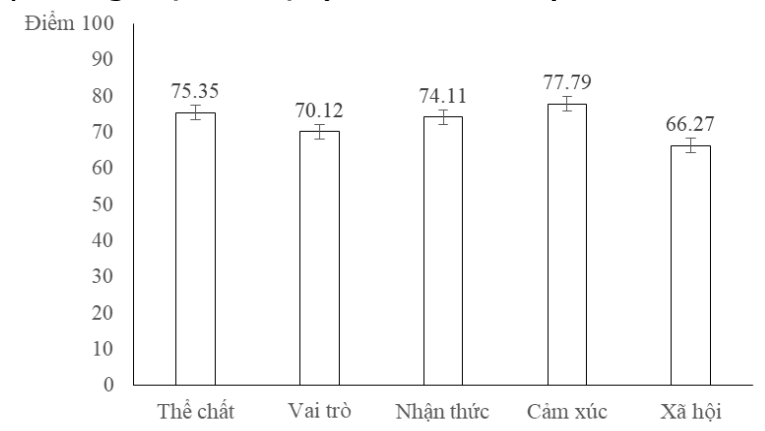

Hinh 2. Điểm chất lượng sống theo thang điểm chức năng

Khía cạnh triệu chứng. CLS của NB UTV HER2 + theo thang đo triệu chứng được khảo sát dựa trên các phương diện bao gồm đau, mệt mỏi, khó thở, buồn nôn/nôn, mất ngủ, chán ăn, táo bón, tiêu chảy và vân đề tài chính. Kết quả khảo sát các khía cạnh thuộc thang điểm triệu chứng được trình bày trong Hình 3.

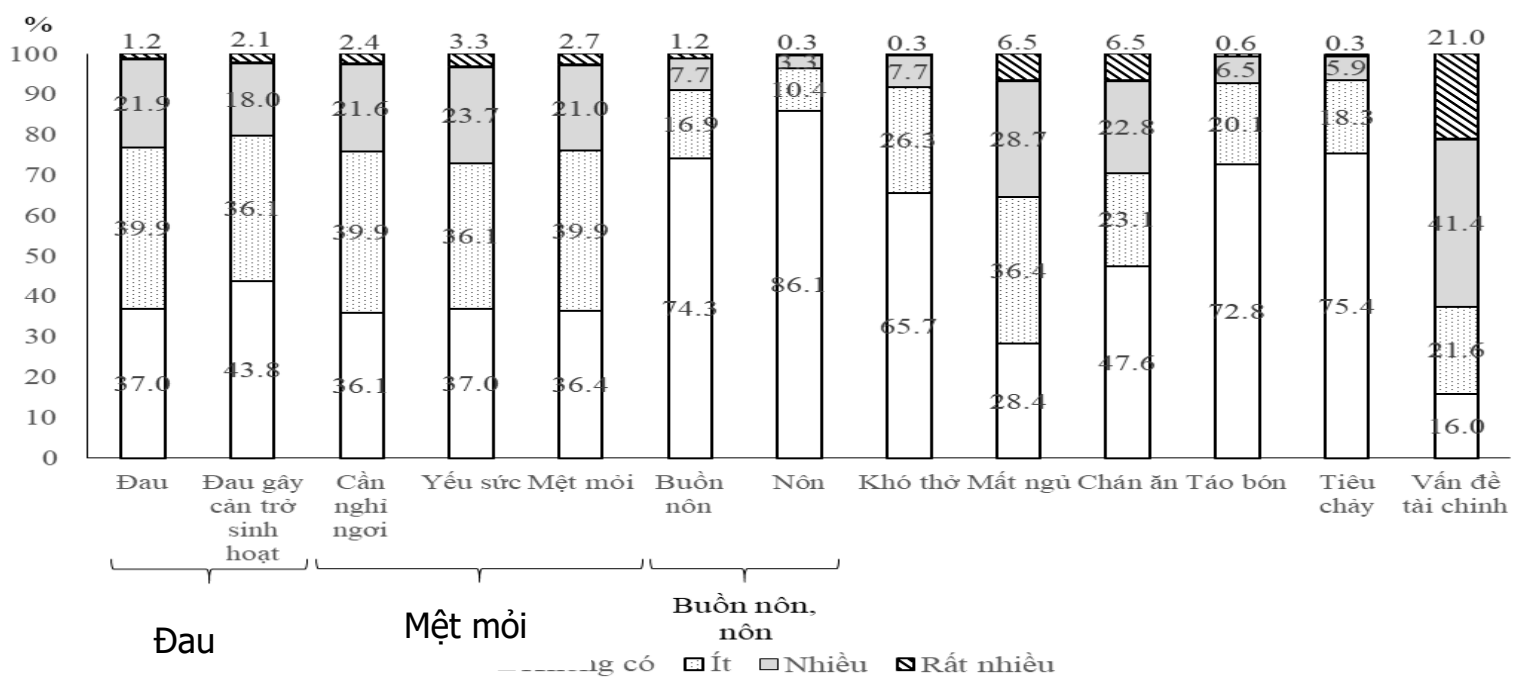

Hình 3. Đánh giá các khía cạnh trong thang điểm triệu chứng 
Theo Hình 3, nghiên cứu ghi nhận:

- Đối với triệu chứng đau, 37,0\% mẫu nghiên cứu không đau ở bất kỳ bộ phận nào trên cơ thể và $43,8 \%$ không bị cản trở sinh hoạt do cơn đau. Ở những NB có ghi nhận về triệu chứng đau, tỉ lệ giảm dần theo mức độ đau tăng dần, với đa phần là đau mức độ nhẹ (39,9\%). Có $36,1 \%$ NB bị cơn đau làm cản trở sinh hoạt thường ngày ở mức độ ít, $18 \%$ ở mức độ nhiều và $2,1 \%$ ở mức độ rất nhiều.

- Đối với triệu chứng mệt mỏi, khoảng $1 / 3$ mẫu nghiên cứu không gặp tình trạng yếu sức, mệt mỏi hay cần nghỉ ngơi. Tỉ lệ NB gặp các vấn đề này ở mức độ nhe lần lượt là $39,9 \% ; 36,1 \%$ và $39,9 \%$. Khoảng $1 / 4$ mẫu nghiên cứu cảm thây mêt mỏi $(21,0 \%)$, yếu sức $(23,7 \%)$ và cần được nghỉ ngơi $(21,6 \%)$ ở mức độ trung bình. Triệu chứng nặng hơn chiếm tỉ lệ tương đối nhỏ (dưới 5\%).

- Đối với triêuu chứng buồn nôn/nôn, phần lớn NB không có biểu hiện buồn nôn hay nôn (chiếm $74,3 \%$ và $86,1 \%$; tương ứng). Có $16,9 \%$ NB buồn nôn và $10,4 \%$ NB nôn ở mức độ nhẹ. Tỷ lệ nhỏ NB có biểu hiện buồn nôn hay nôn ở mức độ nhiều đến rất nhiều ( $8,9 \%$ và $3,6 \%$; tương ứng).

- Đối với các triệu chứng còn lại, đề tài ghi nhận vấn đề mà NB gặp phải nhiều nhất là khó khằn về tài chính (chiểm hơn $80 \%$ ) và mất ngủ (chiếm hơn $70 \%$ ). Tỉ lệ NB mất ngủ mức độ nhẹ và mức độ trung bình đến nặng xấp xỉ nhau, lần lượt là $36,4 \%$ và $35,2 \%$. Có $41,4 \%$ NB gặp khó khăn về tài chinh ở mức độ nhiêu; $21,0 \%$ NB ở mức đô rất nhiều và $21,6 \%$ ở mức đô ít. Hơn $50 \%$ NB gặp tình trạng chán ăn với tỉ lệ xấp xỉ ở mức độ ít và nhiều (lần lượt là $23,1 \%$ và $23,8 \%)$; mức độ rất nhiều chiếm $6,5 \%$. Chỉ khoảng $1 / 4$ đến $1 / 3$ mẫu khảo sát gặp các tình trạng khó thở, táo bón và tiêu chảy, trong đó mức độ ít của các triệu chứng trên chiếm 26,3\%;

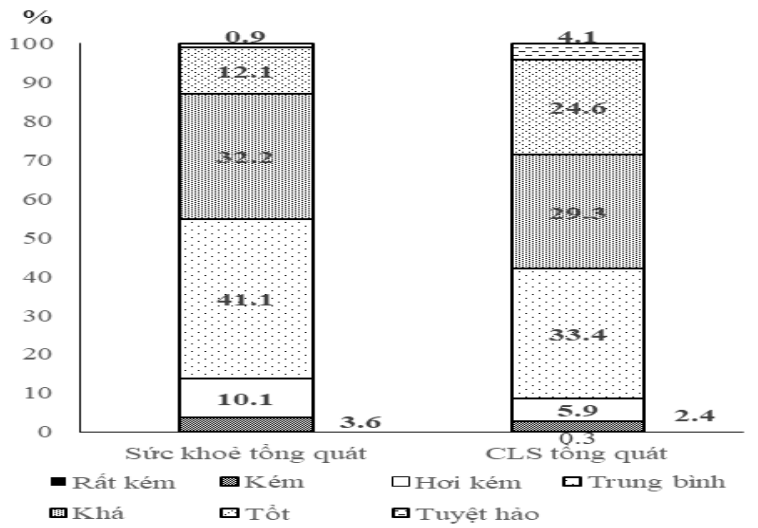

$20,1 \%$; và $18,3 \%$ tương ứng. Mức độ nhiều và rất nhiêuu chiếm $8,0 \% ; 7,1 \%$; và $6,2 \%$.

Điểm triệu chứng của mẫu nghiên cứu được trình bày trong Hình 2.

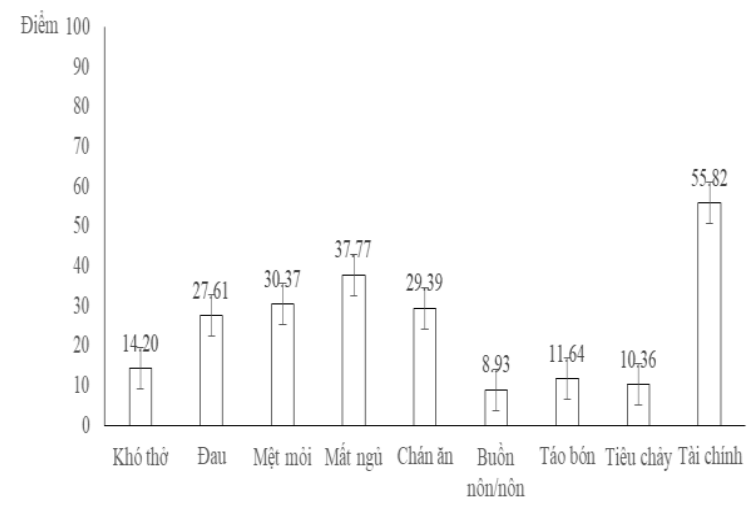

Hình 4. Điểm chất lượng sống theo thang điểm triẹu chứng

Nhìn chung, hâuu hết các triêu chứng đều không vượt quá 50 điểm. Trong đó, mất ngủ là triệu chứng phổ biến và nghiêm trọng nhất $(37,77 \pm 30,11)$. Các vấn đề mệt mỏi, đau nhức và chán ăn có số điểm xấp xỉ nhau và dao động từ $27,61 \pm 22,46$ đến $30,37 \pm 23,54$. Các triệu chứng còn lại rất ít xảy ra hoặc xảy ra với mức đô ít nghiêm trong bao gồm khó thở $(14,20 \pm$ $21,53)$, táo bón $(11,64 \pm 20,93)$, tiêu chảy $(10,36 \pm 19,76)$ và buồn nôn/nôn $(8,93 \pm$ 17,51). Điểm số của khía cạnh tài chính tương đối cao với 55,82 \pm 32,69 điểm, phản ánh gánh nặng kinh tế của bênhh.

Khảo sát điểm CLS tổng quát được thể hiện qua sức khoẻ tổng quát và CLS tổng quát trong 4 tuần gần nhất so với thười điểm khảo sát trên thang đo 7 mức độ, đề tài ghi nhận kết quả được trình bày trong Hình 5 .
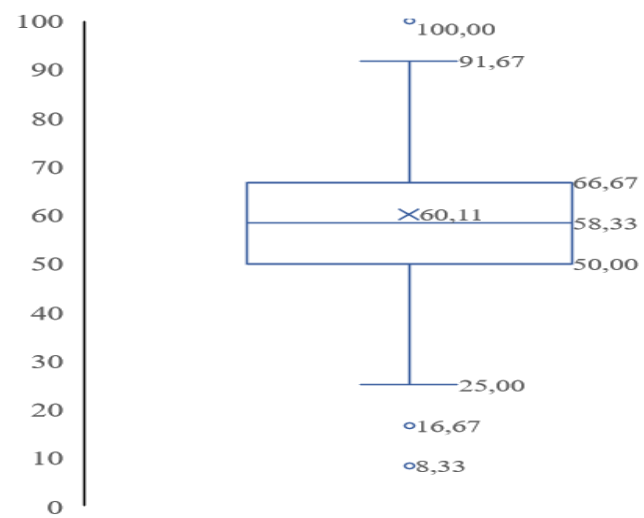

Hình 5. Điểm chất lượng sông theo thang đo tông quát 
Theo Hình 5, phần lớn NB tự đánh giá có sức khoẻ tổng quát và CLS tổng quát xếp loại trung bình đến khá, tương ứng với $41,1 \%$ và $33,4 \%$ ở mức trung bình; $32,2 \%$ và $29,3 \%$ ở mức khá. Có $28,7 \%$ NB tư nhân xét có CLS tổng quát đạt mức tốt đến tuyệt hảo, trong khi đó có 13,0\% NB tự đánh giá sức khoẻ bản thân trong vòng 4 tuần qua đạt mức tốt đến tuyệt hảo. 13,7\% đánh giá sức khỏe tổng quát ở mức hơi kém đến kém. Không có NB nào cảm thấy sức khoẻ bản thân trong vòng 4 tuần ở mức rất kém. Quy về thang điểm 100, nghiên cứu ghi nhận CLS tổng quát trung bình của mẫu nghiên cứu có giá trị 60,11 $\pm 15,79$ điểm với giá trị trung vị 58,33 và được phân loại khá. Điểm CLS dao động từ 8,33 đến 100,0 điểm với tỉ lệ người đạt mức 7 (tương đương 100 điểm) chiếm 0,9\%.

\section{BÀN LUÂ̂N}

Nghiên cứu khảo sát CLS của 338 NB UTV HER2+ điều trị tại 6 BV và ghi nhận độ tuổi trung bình của nhóm nghiên cứu là $53,87 \pm$ 9,97 . Kết quả này phù hợp với mẫu nghiên cứu Phạm Đình Hoàng [5]. Đa phần NB sống ở thành thị (chiếm $71,6 \%$ ). Điều này có thể giải thích do các bệnh viện nghiên cứu đều nằm tại các thành phố trực thuộc trung ương. NB UTV đã phẫu thuật chiếm gần $90 \%$ và đa phần sử dụng phác đồ phối hợp hoá trị và trị liệu đích. Đây là phác đồ được khuyến cáo sử dụng tại Việt Nam [1].

Đối với thang đo chức năng, nghiên cứu ghi nhận các khía cạnh đạt điểm CLS cao nhất bao gồm thể chất (75,36 điểm), cảm xúc $(77,79$ điểm), và nhận thức (74,11 điểm). Điều này tương đồng với các kết quả được công bố với khía cạnh thể chất có số điểm khá cao như nghiên cứu của Phạm Đình Hoàng và cộng sự (77,7 điểm) [5], Nguyễn Văn Cầu (57,85 điểm sau 4 chu kỳ hoá trị; 58,6 điểm sau 8 chu kỳ hoá trị) [2], Nguyễn Thu Hà và cộng sự (85,8 điểm) [4]. Ngoài thể chất, các khía cạnh khác về cảm xúc và nhận thức cũng phù hợp với kết quả các nghiên cứu này. Điều này có thể giải thích do các vấn đề về tuổi tác, thể chất và tinh thần ảnh hưởng đến các mối quan hệ gia đình và xã hội. Ngoài ra, cái nhìn tiêu cực về căn bệnh ung thư là một trong những nguyên do khiến cho người bệnh rơi vào cảm giác lo lắng, tuyệt vọng và thậm chí là trầm cảm, làm hạn chế các hoạt động giao lưu của người bệnh với xung quanh, hậu quả phản ánh qua mức điểm thấp về phương diện xã hội [9].

Đối với thang đo triệu chứng, nghiên cứu ghi nhận các triệu chứng phổ biến và nghiêm trọng mà người bệnh ung thư vú gặp phải bao gồm mất ngủ, chán ăn, đau, mệt mỏi. Trong đó, đau, mệt mỏi và chán ăn là 3 triệu chứng phổ biến được ghi nhận trong nghiên cứu của Phạm Đình Hoàng và cộng sự với mức điểm xấp xỉ nhau (điểm đau - 29,7 điểm; điểm mệt mỏi - 29,7 điểm; điểm chán ăn $-25,3$ điểm) và thấp hơn so với nghiên cứu của Nguyễn Văn Cầu (điểm đau sau 4 chu kỳ - 61,29 điểm; điểm đau sau 8 chu kỳ - 58,33 điểm; điểm mệt mỏi sau 4 chu kỳ 58,78 điểm; điểm mệt mỏi sau 8 chu kỳ - 56,63 điểm) [2]. Điều này có thể giải thích do mẫu nghiên cứu của Nguyễn Văn Cầu là người bệnh di căn và được chỉ định hoá trị liệu. Chính vì vậy, thể chất cùng với tác dụng không mong muốn trong quá trình điều trị khiến các triệu chứng trở nên nghiêm trọng hơn. Ngoài ra, vấn đề tài chính cũng là khía cạnh cần quan tâm khi điểm tài chính có giá trị 55,82 điểm, cao hơn so với nghiên cứu của Phạm Đình Hoàng (32,5 điểm) [5], tương đương với nghiên cứu của Nguyễn Thu Hà và cs $(55,82$ điểm) [4] nhưng thấp hơn so với nghiên cứu của Nguyển Văn Cầu [2]. Kết quả này được giải thích do UTV là căn bệnh gây ra gánh nặng kinh tế lớn cho người bệnh và hệ thống y tế với phần lớn đến từ chi phí thuốc [3].

Đối với thang đo tổng quát, nghiên cứu ghi nhận điểm CLS tổng quát được xếp vào mức khá với tỉ lê cao NB có sức khoẻ tổng quát và CLS tổng quát ở mức trung bình ( $41,1 \%$ và $33,4 \%$, tương ứng). Kết quả này tương đương với nghiên cứu của Phạm Đình Hoàng và cộng sự (66,6 điểm) [5] và nghiên cứu của Nguyễn Thu Hà và cộng sự (58,6 điểm) [4]. Sở dĩ có sự tương đồng này là do phần lớn NB của các mấu nghiên cứu đều ở giai đoạn sớm và điều trị ngoại trú, chính vì vậy tình trạng sức khoẻ tốt hơn, nên điểm CLS cao hơn.

Với các kết quả được ghi nhận ở trên, nghiên cứu vẫn còn một số hạn chế. Thứ nhất, nghiên cứu sử dụng bộ câu hỏi QLQ-C30 dành chung cho các loại ung thư nên chưa đặc trưng cho UTV. Thứ hai, nghiên cứu chỉ khảo sát trên phân nhóm HER2+ nên chưa đánh giá toàn diện CLS của NB UTV nói chung. Theo đó, các nghiền cứu tương lai có thể sử dụng bộ câu hỏi chuyên biệt hơn cho NB UTV và mở rộng mấu nghiên cứu trên bệnh lý UTV ở các giai đoạn khác nhau.

\section{KẾT LUẬN}

Người bệnh ung thư vú HER2-dương tính có chất lượng sống ở mức khá với điểm chất lượng sống tổng quát $60,11 \pm 15,80$ điểm. Chức nằng thể chất, cảm xúc và nhận thức có điểm số 
tương đối tốt, tuy nhiên quá trình điều trị mang lại khó khăn tài chính cho người bệnh.

\section{TÀI LIÊU THAM KHẢO}

1. Lưởng Ngọc Khuê M. T. K. (2020), Hướng dẫn chẩn đoán và điều trị ung thư vú, 3128/QĐ-BYT, Bộ Y tế, Hà Nội.

2. Nguyê̂n Văn Câu (2020), Nghiên cứu điều tri ung thư vú giai đoạn di căn bằng hóa trị phối hợp anthracycline và taxane, Sản phụ khoa, Đại học $Y$ Dước Hữé.

3. NNguyển Thị Thu Thuỷ và cs. (2014), "Đánh giá gánh nặng kinh tế bệnh ung thư vú tại Việt Nam". 18, pp. 319-323.

4. Nguyễn Thu Hà và cs. (2017), "Chất lượng cuộc sống của người bệnh ung thư vú sử dụng thang đo QLQ-C30 và một số yếu tố liên quan tại một số bệnh viện Ung bướu tại Việt Nam", Tạp Chí Y học Dự Phòng. 27 (5).

5. Phàm Đ̇ình Hoàng và cs. (2019), "Đánh giá chẩt lượng cuộc sống của bệnh nhân nữ ung thư vú được điều trị tại Bệnh viện Quận Thủ Đức", Tạp chí Y học TP.HCM. 23 (5), pp. 141-147.

6. Do T. T. et al. (2020), "Contamination, suffering and womanhood: Lay explanations of breast cancer in Central Vietnam", Social Science \& Medicine. 266, pp. 113360.

7. Ho P. J. et al. (2018), "Health-related quality of life in Asian patients with breast cancer: a systematic review", BMJ Open. 8 (4), pp. e020512.

8. Sung H. et al. (2021), "Global Cancer Statistics 2020: GLOBOCAN Estimates of Incidence and Mortality Worldwide for 36 Cancers in 185 Countries", CA Cancer J Clin. 71 (3), pp. 209-249.

9. Tsaras K. et al. (2018), "Assessment of Depression and Anxiety in Breast Cancer Patients: Prevalence and Associated Factors", Asian Pac J Cancer Prev. 19 (6), pp. 1661-1669.

10. Fayers P. M., N. Aaronson, and $K$. Bjordal, "The EORTC QLQ-C30 scoring manual (3rd Edition)", Journal of the National Cancer Institute 1993. 85, pp. 365-376.

\section{CHẨN ĐOÁN VÀ XỬ TRÍ MộT TRƯờNG HỢP CHẢY DỊCH NÃO TỦY Ở NGÁCH BÊN XOANG BƯỚM}

Ngô Văn Công*

\section{TÓM TẮT}

Bệnh nhân nữ 45 tuổi, vào viện vì chảy dịch não tủy qua mũi. Qua khám, xét nghiệm và chụp CT/MRI đã được chẩn đoán xác định chảy dịch não tủy ngách bên xoang bướm bên trái. Bênh nhân được phâuu thuâtt nội soi mở rộng qua mũi tìm lổ rò. Xác định vị trí khuyết xương tại phần trần của ngách bền xoang bướm trái. Bít lồ rò với kỹ thuật nhiều lớp (mở và vạt mũi vách ngăn). Sau đó dẫn lưu thắt lưng. Với kết quả ban đâu thành công.

Tư khóa: rò dịch não tủy, rò dịch não tủy ngách bên xoang bướm.

\section{SUMMARY \\ TO DIAGNOSIS AND TREATMENT A LATERAL SPHENOID RECESS CEREBROSPINAL LEAK CASE}

A patient was 45 year old female. She had a main complaint which was cerebrospinal fluid escape through her left nostril. The patient has examined laboratory and took CT/ MRI for her. Final diagnosis is left lateral sphenoid recess cerebrospinal leak. She was operated transnasal expanded endoscopic sinus surgery to find a defective position. We identify a bone dehiscient which is a top of the lateral sphenoid recess

*Bệnh viện Chợ Rẫy

Chịu trách nhiệm chính: Ngô Văn Công

Email: congtmh@gmail.com

Ngày nhận bài: 2.6.2021

Ngày phản biên khoa học: 2.8.2021

Ngày duyệt bài: 10.8.2021 into left. The patient is applied multiple layers technique to repair skull base defect. In addition, the patient was performed lumbar drainage. The initial result of treatment is successful

Keywords: cerebrospinal fluid, lateral sphenoid recess cerebrospinal leak.

\section{I. ĐăT VẤN ĐỀ}

Chảy dịch não tủy từ ngách bên của xoang bướm thì hiếm gặp; tỷ lệ chảy dịch não tủy qua ngách bên xoang bướm theo y vằn khoảng $7,7 \%$ [5]. Việc xác định vị trí \% kích thước khuyết của sàn sọ quyết định phương pháp tiếp cận và kỹ thuật điêuu trị. Phương pháp tiếp cận nội soi qua mũi để bít rò dich não tủy được khuyến cáo nhiều với tỷ lệ thành công khoảng 90\% [1]. Tuy nhiên, vẫn có khả năng tái phát cao bởi do khuyết ngách bên của xoang bướm là vị trí tiếp cận khó về mặt giải phẫu. Bên cạnh đó, nguyên nhân gây thoát dịch não tủy vùng này thường do tăng áp lực nội sọ. Nên việc chẩn đoán và điêu chảy dịch não tủy qua ngách bên xoang bướm luôn là thách thức cho các Bác sĩ Tai Mũi Họng.

\section{CA LÂM SÀNG}

Bệnh nhân nữ 45 tuổi, vào viện vì chảy dịch trong qua mũi khi cuối đâuu trên 2 năm. Kèm theo chảy dịch mũi trái bao gồm ù tai, nghe kém bên trái, đau đâu thỉnh thoảng. Khám lâm sàng mũi thoáng, không u bướu, tai 2 bên không ứ dịch, màng nhĩ trong. 